\title{
Heterogeneous expression of DNA-dependent protein kinase in esophageal cancer and normal epithelium
}

\author{
NORIO TONOTSUKA ${ }^{1,2}$, YOSHIO HOSOI ${ }^{4}$, SHUKICHI MIYAZAKI ${ }^{2}$, GO MIYATA $^{2}$, KO SUGAWARA ${ }^{2}$, \\ TAKAHIRO MORI $^{3}$, NORIAKI OUCHI ${ }^{3}$, SUSUMU SATOMI $^{2}$, YOSHIHISA MATSUMOTO $^{4}$, \\ KEIICHI NAKAGAWA ${ }^{5}$, KIYOSHI MIYAGAWA ${ }^{4}$ and TETSUYA ONO ${ }^{1}$ \\ ${ }^{1}$ Department of Radiation Research, ${ }^{2}$ Division of Advanced Surgical Science and Technology and ${ }^{3}$ Division of \\ Surgical Oncology, Faculty of Medicine, Tohoku University, Sendai 980-8575; Departments of ${ }^{4}$ Radiation \\ Research and ${ }^{5}$ Radiology, Faculty of Medicine, University of Tokyo, Tokyo 113-0033, Japan
}

Received February 10, 2006; Accepted April 13, 2006

\begin{abstract}
Esophageal cancer tissues and adjacent normal mucosae in 13 patients with primary esophageal cancer were examined for quantitative differences in DNA-dependent protein kinase (DNA-PK) activity and for expressions of $\mathrm{Ku} 70, \mathrm{Ku} 80$ and DNA-PKcs proteins by Western blotting and immunohistochemistry. The tumor tissues showed higher DNA-PK activity than the normal mucosae. Protein levels of $\mathrm{Ku} 70$, Ku80 and DNA-PKcs correlated with DNA-PK activities in the tumor tissues. Immunohistochemical analysis revealed that $\mathrm{Ku} 70, \mathrm{Ku} 80$ and DNA-PKcs located predominantly in the nuclei in both the tumor tissues and normal mucosae. In the normal epithelium, Ku70, Ku80 and DNA-PKcs were expressed only in the nuclei of the basal cell layers and not in those of the lumenal cell layers. In the tumor tissues, the expressions of DNA-PK proteins showed intratumoral heterogeneity. The different portions in the same tumor showed different expression levels of DNA-PK proteins, and even each tumor cell showed different expression levels. These results suggest that cell differentiation and tumor progression affect cellular DNA-PK protein levels and its activity. Furthermore, the intratumoral heterogeneity of DNA-PK protein expression in esophageal cancer cells/ tissues also suggests the difficulty in prediction of radio- or chemo-sensitivity of the tumor through estimation of DNA-PK activity/protein levels in tumor specimens.
\end{abstract}

\section{Introduction}

DNA-dependent protein kinase (DNA-PK) is a nuclear protein with serine/threonine kinase activity and it composed

Correspondence to: Dr Yoshio Hosoi, Department of Radiation Research, Faculty of Medicine, University of Tokyo, 7-3-1 Hongo, Bunkyoku, Tokyo 113-0033, Japan

E-mail: hosoi@m.u-tokyo.ac.jp

Key words: DNA-dependent protein kinase, esophageal cancer, Ku70, Ku80, DNA-PKcs of the catalytic subunit of DNA-PK (DNA-PKcs) and a heterodimer of Ku70 and Ku80 (1). DNA-PK plays a crucial role in the repair of DNA double-strand breaks (DSBs) induced by ionizing radiation and chemotherapeutic agents (1). Cells lacking DNA-PK activity because of defects in the DNA-PK components show hypersensitivity to ionizing radiation and chemotherapeutic agents (2-6).

There have been many reports on the examination whether DNA-PK activity correlates with radiation sensitivity and whether it can be a parameter indicating the sensitivity to radiotherapy and/or chemotherapy. Suppression of DNA-PK activity by a phosphatidylinositol 3-kinase inhibitor wortmannin, antisense Ku70/DNA-PKcs, or small inhibitory RNA for DNA-PKcs sensitized cells to ionizing radiation (7-10). Polischouk et al reported that levels of DNA-PK activity associate with the proficiency in rejoining of DNA doublestrand breaks (11). These results indicate that levels of DNAPK activity correlates with cellular sensitivity to ionizing radiation in the cells under the same genetic background. Relationship between radiation sensitivity and DNA-PK activity/protein levels under different genetic backgrounds has been investigated in cultured cell lines or tissue specimens obtained from patients with cancer (11-20). The results reported were contradictory and it is still unclear whether DNA-PK can be a parameter indicating radiation sensitivity under different genetic backgrounds.

To predict curability of the tumor after radiotherapy or chemotherapy, the sensitivities in both tumor tissue and adjacent normal tissue should be assessed. We previously examined the DNA-PK activities in tumor tissues and adjacent normal tissues in patient with colorectal cancer and found that the tumor tissues showed higher DNA-PK activity than the adjacent normal tissues in 11 out of 12 patients, which suggests poor curability of the tumors after radiation therapy alone under the condition that the DNA-PK activity correlates with radiation sensitivity (21). In the present study, we examined DNA-PK activities and protein levels of the tumor tissues and the adjacent normal mucosae in patients with esophageal cancer by the standard kinase activity assay, Western blotting and immunohistochemistry. The results revealed that DNA-PK activity was higher in esophageal 
Table I. Characteristics of the patients.

\begin{tabular}{|c|c|c|c|c|c|}
\hline Patient No. & Sex & Position $^{\mathrm{a}}$ & Histology ${ }^{\mathrm{b}}$ & Differentiation & pTNM $^{\mathrm{c}}$ \\
\hline 1 & M & $\mathrm{Lt}$ & $\mathrm{SCC}$ & Poorly differentiated & III \\
\hline 2 & $\mathrm{~F}$ & Mt & SCC & Well differentiated & III \\
\hline 3 & $\mathrm{~F}$ & Mt & SCC & Poorly differentiated & I \\
\hline 4 & M & $\mathrm{Ce}$ & SCC & Poorly differentiated & III \\
\hline 5 & M & Mt & SCC & Moderately differentiated & I \\
\hline 6 & M & Mt & $\mathrm{SCC}$ & Well differentiated & III \\
\hline 7 & $\mathrm{~F}$ & $\mathrm{Lt}$ & Undifferentiated & Undifferentiated & IIB \\
\hline 8 & $\mathrm{~F}$ & $\mathrm{Lt}$ & SCC & Moderately differentiated & IIB \\
\hline 9 & M & Mt & Basaloid & - & III \\
\hline 10 & $\mathrm{~F}$ & $\mathrm{Mt}$ & SCC & Well differentiated & I \\
\hline 11 & M & $\mathrm{Lt}$ & SCC & Poorly differentiated & IIA \\
\hline 12 & M & $\mathrm{Ae}$ & SCC & Poorly differentiated & IIB \\
\hline 13 & M & Mt & SCC & Poorly differentiated & I \\
\hline
\end{tabular}

${ }^{a}$ Ce, cervical esophagus; Mt, middle thoracic esophagus; Lt, lower thoracic esophagus; Ae, abdominal esophagus. ${ }^{b S C C}$, squamous cell carcinoma; undiffrentiated, Undifferentiated carcinoma (small cell type); basaloid, basaloidcarcinoma. ${ }^{\mathrm{c}} \mathrm{TNM}$, pathological stage grouping according to TNM classification.

cancer tissues than in the normal mucosae and that the levels of DNA-PK proteins correlated with the DNA-PK activity. Expressions of DNA-PK proteins in tumor tissues were found to be heterogeneous, which suggests the difficulty in prediction of radio- or chemo-sensitivity of the tumors thorough the examination of DNA-PK activity/protein levels in tumor specimens of esophageal cancer.

\section{Materials and methods}

Tissue specimens. All esophageal tumors and adjacent normal tissues were obtained at the time of surgery at Tohoku University Hospital from 1999 to 2000. Informed consent was received from all patients. The patients received neither radiotherapy nor chemotherapy before surgery. Characteristics of the patients are shown in Table I.

Cells. LM217 is an SV40 transformed human fibroblast cell line derived from HS27 (22). LM217 was used as control in measurement of DNA-PK activity and Western blotting.

Whole-cell and tissue extracts. Whole-cell extracts and tissue extracts were prepared by a modification of the methods of Finnie et al and Dignam et al $(23,24)$. The samples were washed twice with Tris-buffered saline $[2 \mathrm{mM}$ Tris $(\mathrm{pH} 7.2)$, $150 \mathrm{mM} \mathrm{NaCl}$, homogenized using a hand-operated homogenizer (Eppendorf, Hamburg, Germany), then suspended in $100 \mu 1$ of a low-salt buffer [10 mM HEPES (pH 7.2), $25 \mathrm{mM}$ $\mathrm{KCl}, 10 \mathrm{mM} \mathrm{NaCl}, 1.1 \mathrm{mM} \mathrm{MgCl}_{2}, 1 \mathrm{mM}$ EDTA, $1 \mathrm{mM}$ EGTA, $1 \mathrm{mM}$ PMSF, $1 \mathrm{mM}$ DTT, $1 \mu \mathrm{g} / \mathrm{ml}$ pepstatin, $1 \mu \mathrm{g} / \mathrm{ml}$ leupeptin, $1 \mu \mathrm{g} / \mathrm{ml}$ antipain], and then frozen in liquid nitrogen and thawed at $30^{\circ} \mathrm{C}$ three times. After a 60 -min incubation at $4^{\circ} \mathrm{C}$, the suspension was adjusted to $0.4 \mathrm{M} \mathrm{KCl}$ by adding $3.5 \mathrm{M} \mathrm{KCl}$, incubated for $30 \mathrm{~min}$ at $4^{\circ} \mathrm{C}$, and centrifuged for $10 \mathrm{~min}$ at $15,000 \mathrm{rpm}$. The supernatant was designated as the whole-cell extract (25). Protein concentrations were determined with the Bio-Rad protein assay (Bio-Rad, Hercules, CA).
$D N A-P K$ activity. DNA-PK activity was assayed as previously described, with a synthetic peptide (EPPLSQEAFAD LWKK) (7). The whole-cell or tissue extracts were incubated in $20 \mu \mathrm{l}$ of kinase buffer [ $20 \mathrm{mM}$ HEPES-NaOH ( $\mathrm{pH} 7.2$ ), $100 \mathrm{mM} \mathrm{KCl}, 5 \mathrm{mM} \mathrm{MgCl}$, $1 \mathrm{mM}$ DTT, $0.5 \mathrm{mM} \mathrm{NaF}, 0.5 \mathrm{mM}$ ß-glycerophosphate, $0.2 \mathrm{mM}$ ATP, $10 \mu \mathrm{Ci} / \mathrm{ml}\left[\gamma_{-}{ }^{32} \mathrm{P}\right] \mathrm{ATP}$ in the presence of $0.01 \mathrm{mg} / \mathrm{ml}$ sonicated salmon sperm DNA and $0.5 \mathrm{mg} / \mathrm{ml}$ substrate peptide] at $37^{\circ} \mathrm{C}$ for $15 \mathrm{~min}$. The final protein concentration in the reaction mixture was $37.5 \mu \mathrm{g} / \mathrm{ml}$. The reactions were stopped by the addition of $20 \mu 1$ of $30 \%$ acetic acid and the mixtures were spotted onto P81 paper disks (Whatman International Ltd., Maidstone, UK). The disks were washed 4 times in $15 \%$ acetic acid. Radioactivity in the paper disks was measured in a liquid scintillation counter.

Western blotting. Whole cell extracts or tissue extracts were lysed in the electrophoresis sample buffer [62.5 mM Tris (pH 6.8), 2\% SDS, 5\% glycerol, $0.003 \%$ bromophenol blue, $1 \%$ B-mercaptoethanol] and boiled for $5 \mathrm{~min}$. The lysate was resolved by electrophoresis using a gradient gel (Daiichi Pure Chemicals Co., Ltd., Tokyo, Japan), and was electrophoretically transferred to polyvinylidene difluoride membranes (Bio-Rad). The membranes were then proved with anti-Ku70 antibody, anti-Ku80 antibody, anti-DNA-PKcs antibody Ab-4 (Cocktail) (NeoMarkers, Fremont, CA) or Anti-GAPDH antibody (Trevigen, Inc., Gaithersburg, MD). The anti-Ku70 and anti-Ku80 antibodies used were raised in our laboratory as previously reported (19). The antigen-antibody complexes were detected by the ECL Plus ${ }^{\mathrm{TM}}$ Western blotting detection reagents (Amersham Pharmacia Biotech Inc., Piscataway, NJ), with horseradish peroxidase-conjugated antibodies. The images were analyzed with the Scion Image Beta 4.02 Win software (Scion Corporation, Frederick, MD) to quantify the densities of bands corresponding to Ku70, Ku80, DNA-PKcs and GAPDH.

Immunohistochemistry for DNA-PK proteins. Formalin-fixed and paraffin-embedded tissue specimens were deparaffinized, 

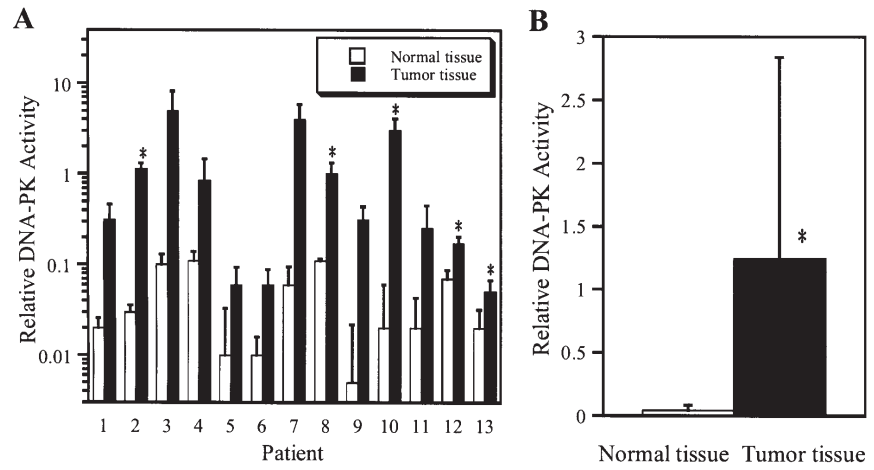

Figure 1. DNA-PK activities of tumor tissues and adjacent normal mucosae in 13 patients with esophageal cancer. DNA-PK activities are expressed as values relative to that of LM217, which is set to a value of 1. (A) Mean \pm SD of DNA-PK activities of three different specimens of tumor tissues and normal tissues in each patient, ${ }^{*} \mathrm{P}<0.05$. (B) Average values of DNA-PK activities of tumor tissues and normal tissues in 13 patients. Mean $\pm \mathrm{SD}$, ${ }^{*} \mathrm{P}<0.05$.

cut to $2-\mu$ sections, and stained by the labeled streptavidin biotin (LSAB) technique. Briefly, the sections were incubated with $3 \%$ hydrogen peroxide in methanol, and then incubated with $1 \%$ bovine serum for 30 min for blocking. The sections were incubated with primary antibody overnight at room temperature, and incubated with biotinylated secondary antibody (Nichirei Biosciences Inc., Tokyo, Japan) for $30 \mathrm{~min}$ at room temperature. Then, streptavidin/biotin complex was applied for $30 \mathrm{~min}$ (Nichirei Biosciences Inc.), followed by a 30 min incubation in 3,3'-diaminobnzidine substrate, yielding a brown reaction product. Sections were counterstained with hematoxylin and mounted under a coverslip.

Evaluation. The intensity of staining in immunohistochemistry was evaluated by the expression score reported by Rigas et al (26). The intensity of staining was rated according to the following scale: 2 = intense brown staining, $1=$ light brown staining, $0=$ no staining. In each sample, the percentage of cells expressing each protein was determined. To obtain a numerical assessment of the expression of each protein, we calculated the multiple of the intensity of staining by the percentage of cells expressing a protein for each sample. In tumor tissues, we assessed the expression score at the growing edge of the carcinoma, which is defined as the invasive tip, because tumor growth largely depends on the proliferative kinetics at the invasive tip (27). In normal tissues, the expression score was assessed at the normal mucosae. Each expression score was expressed as mean \pm SD of three scores evaluated at the three different fields in the invasive tip or in normal mucosae respectively with original magnification of x400.

Statistics. Homogeneity of variance was tested by the F-test. When variance was homogeneous, Student's t-test was used. When variance was heterogeneous, Welch's test was used. For analysis of correlation coefficient, the distributions of variables were tested first. When variables were normally distributed, Peason's correlation coefficient test was used. When variables were not normally distributed, Spearman's rank correlation coefficient test was used. Differences were considered to be statistically significant at $\mathrm{P}<0.05$.
A
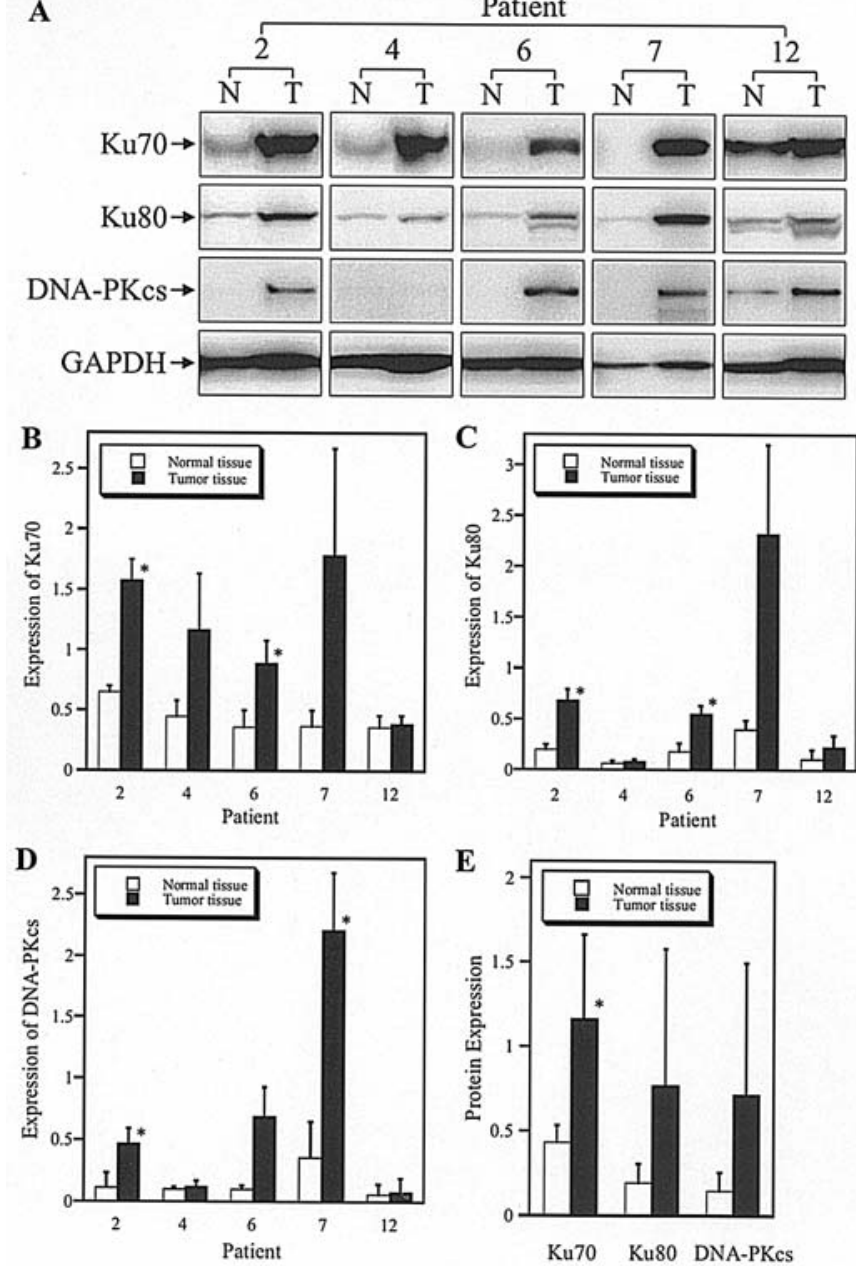

Figure 2. Expression of DNA-PK proteins in normal mucosae and tumor tissues. (A) Western blot analysis for Ku70, Ku80, DNA-PKcs and GAPDH in the extracts prepared from tumor tissues $(\mathrm{T})$ and normal mucosae $(\mathrm{N})$ obtained from patients No. 2, 4, 6, 7 and 12. (B-D) Relative protein levels of $\mathrm{Ku} 70, \mathrm{Ku} 80$ and DNA-PKcs in the 5 patients. Histograms represent the scanning densitometric analysis of Western blots. Each value is normalized for GAPDH and expressed as a value relative to that of LM217, which is set to a value of 1 . Mean \pm SD of the data from three different tissue extracts used in the measurement of DNA-PK activity. (E) Average values of Ku70, Ku80 and DNA-PKcs protein levels of tumor tissues and normal tissues in the 5 patients. Mean $\pm \mathrm{SD},{ }^{*} \mathrm{P}<0.05$.

\section{Results}

DNA-PK activity of tumor tissues and normal mucosae. We examined DNA-PK activities of tumor tissues and adjacent normal mucosae in 13 patients with esophageal cancer. In 5 patients, DNA-PK activity was significantly higher in the tumor tissue compared with the normal mucosa (Fig. 1A). Average value of the DNA-PK activities of the tumor tissues in the 13 patients was significantly higher than that of the normal mucosae (Fig. 1B).

Expression of DNA-PK proteins in tumor tissues and normal mucosae. Next, we examined DNA-PK protein levels by Western blotting in order to investigate whether the variety of DNA-PK activities observed in tumor tissues and normal mucosae depended on the DNA-PK protein levels. For the Western blotting, we used the same tissue extracts as used in the assessments of DNA-PK activity. Western blotting was 
conducted using the tissue extracts from the 5 patients whose had enough tissue extracts for the Western blot analysis (Fig. 2A). In 2 out of the 5 patients, levels of Ku70, $\mathrm{Ku} 80$ and DNA-PKcs proteins were significantly higher in the tumor tissue compared with the normal mucosae (Fig. 2B-D). Average value of $\mathrm{Ku} 70$ protein levels in the 5 patients was significantly higher in the tumor tissue (Fig. 2E). Significant correlation was observed between DNA-PK activity and protein levels of Ku70, Ku80 and DNA-PKcs in tumor tissues of the 5 patients (Table IIB). Ku70 and Ku80 protein levels correlated with DNA-PKcs protein level in the tumor tissues (Table IIB). Ku70 protein level correlated with Ku80 protein level in the normal tissues (Table IIA).

Immunohistochemical analysis in normal mucosae. Esophageal epithelium consists of non-keratinized stratified squamous cells as shown in Fig. 3A. Stainings for Ku70, Ku80 and DNA-PKcs were predominantly nuclear and they showed a similar pattern (Fig. 3B-E). In the epithelium, Ku70, Ku80 and DNA-PKcs were expressed exclusively in the nuclei of the basal cell layers and not in those of the lumenal cell layers (Fig. 3B-D). The DNA-PK proteins were expressed in almost all the nuclei in the middle-basal cell layers of the epithelium, whereas they were not expressed in some nuclei in the most basal cell layers (Fig. 3B-D). In lamina propria and muscularis mucosa, the DNA-PK proteins were expressed in about half of the nuclei (Fig. 3B-D).

Immunohistochemical analysis in tumor tissues. In tumor tissues, stainings for Ku70, Ku80 and DNA-PKcs were also predominantly nuclear and they showed a similar pattern in each tumor (Figs. 4 and 5). The intensity of staining was heterogeneous in the tumor tissues (Figs. 4B-D and 5B-D). The different portions in the same tumor showed different expression levels of DNA-PK proteins, and even each tumor cell showed different expression levels (Figs. 4F-H and 5F-H). These heterogeneic staining patterns of the DNA-PK proteins could be observed in all the tumors examined.

A semi-quantitative assessment of DNA-PK proteins. To assess the expression of DNA-PK proteins semi-qantitatively in immunohistochemical examination, the intensity of staining was evaluated by the expression score described in Materials and methods. The expression score was significantly higher in the tumor tissue than in the normal mucosa in 7 patients for $\mathrm{Ku} 70,4$ patients for $\mathrm{Ku} 80$ and 6 patients for DNA-PKcs (Fig. 6A-C). In 2 patients, the expression score for DNA-PKcs was lower in the tumor tissue than in the normal mucosa (Fig. 6C). The average values of expression scores for $\mathrm{Ku} 70$ and $\mathrm{Ku} 80$ in 13 patients were significantly higher in the tumor tissue than in the normal mucosa (Fig. 6D).

\section{Discussion}

Prediction of radio- and chemo-sensitivity of normal and tumor tissues before the treatment will provide crucial information to find the best treatment method for each patient with cancer. In most of the cells, cell survival after X-irradiation depends on the yield of DNA DSBs and the repair of them. Non-homologous end-joining (NHEJ) and homologous
Table II. Correlation coefficient.

A, Correlation coefficients in normal tissues

\begin{tabular}{|c|c|c|c|c|c|c|}
\hline & \multicolumn{2}{|c|}{$\mathrm{Ku} 70$} & \multicolumn{2}{|c|}{ Ku80 } & \multicolumn{2}{|c|}{ DNA-PKcs } \\
\hline & $\mathrm{P}$ & $\mathrm{CC}$ & $\mathrm{P}$ & $\mathrm{CC}$ & $\mathrm{P}$ & $\mathrm{CC}$ \\
\hline $\begin{array}{l}\text { DNA-PK } \\
\text { activity }\end{array}$ & 0.323 & -0.491 & 0.258 & -0.550 & 0.975 & 0.975 \\
\hline Ku70 & - & - & 0.0401 & 0.816 & 0.725 & 0.157 \\
\hline Ku80 & 0.041 & 0.816 & - & - & 0.544 & 0.271 \\
\hline DNA-PKcs & 0.725 & 0.157 & 0.544 & 0.271 & - & - \\
\hline
\end{tabular}

$\mathrm{B}$, Correlation coefficients in tumor tissues

\begin{tabular}{|c|c|c|c|c|c|c|}
\hline & \multicolumn{2}{|c|}{$\mathrm{Ku} 70$} & \multicolumn{2}{|c|}{ Ku80 } & \multicolumn{2}{|c|}{ DNA-PKcs } \\
\hline & $\mathrm{P}$ & $\mathrm{CC}$ & $\mathrm{P}$ & $\mathrm{CC}$ & $\mathrm{P}$ & $\mathrm{CC}$ \\
\hline $\begin{array}{l}\text { DNA-PK } \\
\text { activity }\end{array}$ & 0.0476 & 0.832 & 0.00580 & 0.937 & 0.0100 & 0.917 \\
\hline $\mathrm{Ku} 70$ & - & - & 0.101 & 0.728 & 0.000285 & 0.986 \\
\hline Ku80 & 0.101 & 0.728 & - & - & 0.000284 & 0.986 \\
\hline
\end{tabular}

$\begin{array}{lllll}\text { DNA-PKcs } & \mathbf{0 . 0 0 0 2 8 5} & 0.986 & \mathbf{0 . 0 0 0 2 8 4} & 0.986\end{array}$

CC, correlation coefficient. Bold values indicating $\mathrm{P}<0.05$.

recombination (HR) are the two major repair mechanisms for DSBs, and NHEJ plays the most important role in mammalian cells (28). Radiation sensitivity can be possibly predicted through the quantitative evaluation of DNA-PK as a key enzyme for NHEJ because DNA-PK activity has relevance to cellular sensitivity to ionizing radiation and DNA-PK protein levels correlate with DNA-PK activity (7-11). In the present study, the immuno-histochemical analysis revealed the intratumoral heterogeneity of DNA-PK protein expression (Figs. 4 and 5). The different portions in the same tumor showed different expression levels of DNA-PK proteins, and even each tumor cell showed different expression levels (Figs. 4 and 5). This heterogeneous expression of DNA-PK proteins in esophageal cancer tissues suggests the difficulty in prediction of curability of the tumors after radiotherapy or chemotherapy through evaluation of DNA-PK protein levels in the tumor specimens because the curability will reflect the DNA-PK protein levels in the cells that express DNA-PK most abundantly in the tumor under the condition that radiation sensitivity correlates with DNA-PK activity.

In the present study, DNA-PK activity correlated with protein levels of Ku70, Ku80 and DNA-PKcs, and protein levels of Ku70 and Ku80 correlated with the levels of DNAPKcs in tumor tissues (Table II). These results correspond with previous reports $(16,18,20,21)$. Promoter regions of $K u 70$, $K u 80$ and DNA-PKcs contain consensus Sp1 recognition elements and therefore these genes are supposed to be regulated by the same transcriptional factor, $\operatorname{Sp} 1(21,29,30)$. 

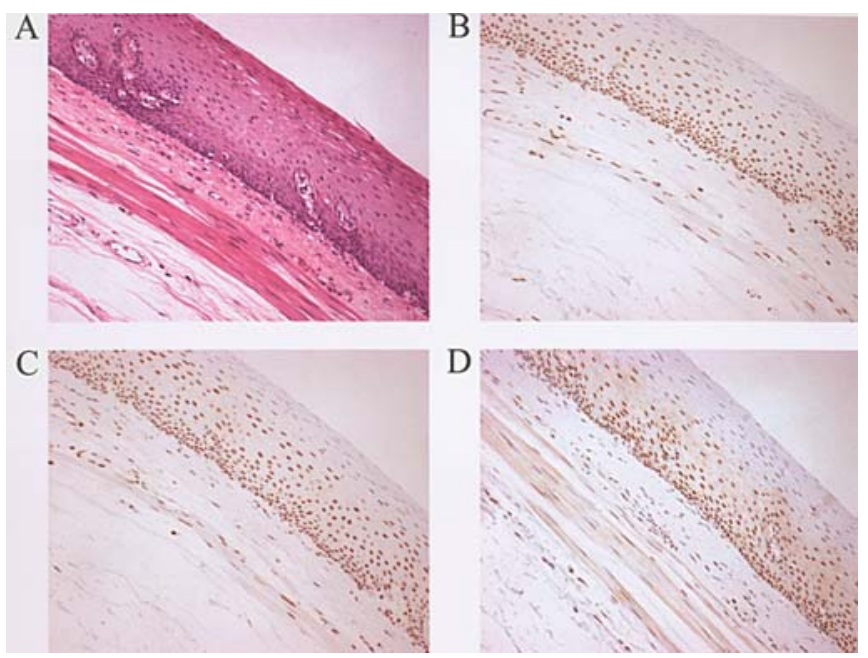

Figure 3. The expression of DNA-PK proteins in esophageal mucosae from patient No. 7. (A) Staining with hematoxylin and eosin. (B) Immunostaining for Ku70. (C) Immunostaining for Ku80. (D) Immunostaining for DNA-PKcs. Original magnification $\mathrm{x} 100$.
A

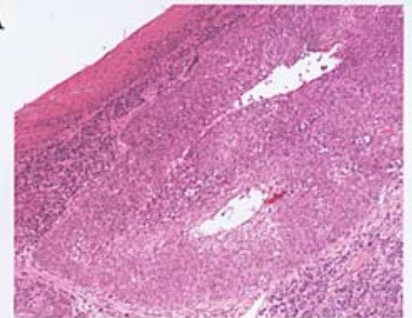

C
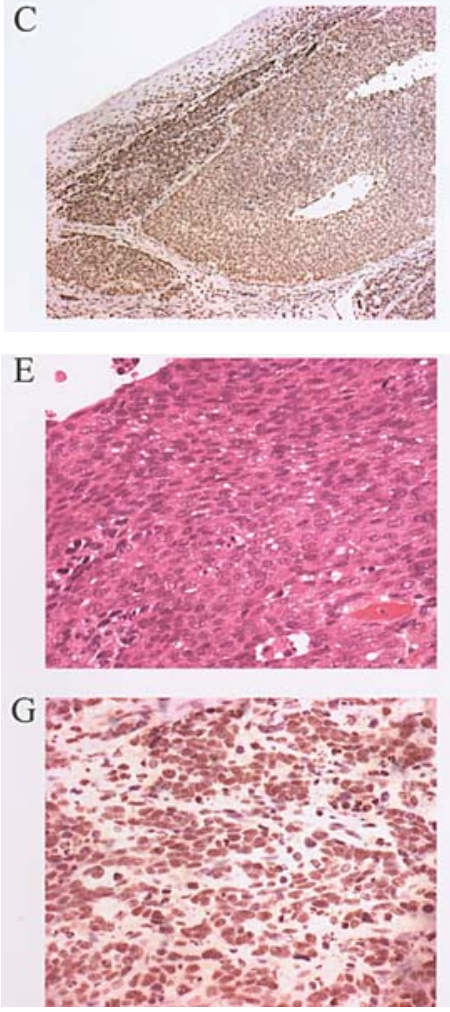
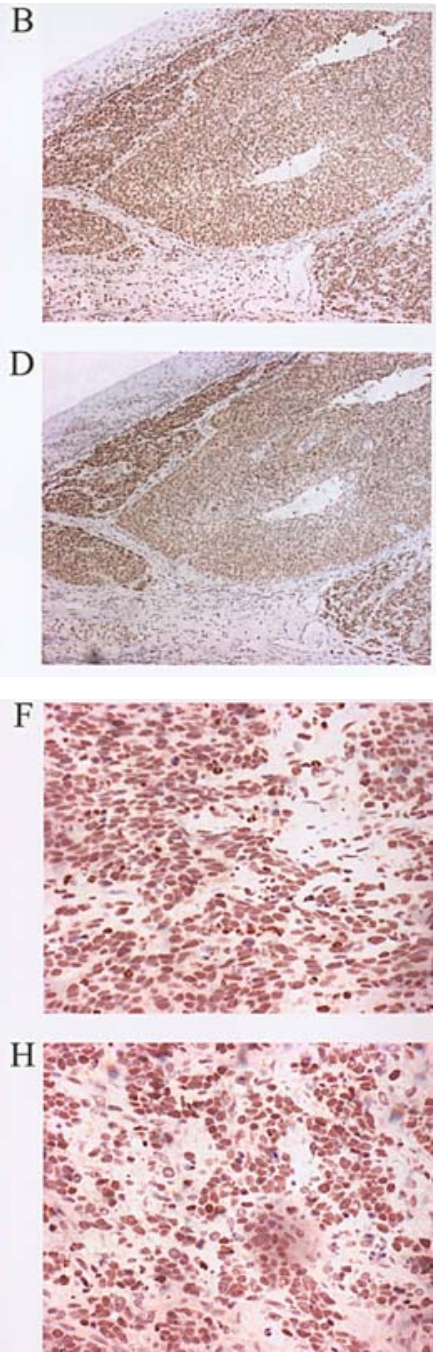

Figure 4. The expression of DNA-PK proteins in esophageal cancer tissues from patient No. 7. (A and E) Staining with hematoxylin and eosin. (B and F) Immunostaining for Ku70. (C and G) Immunostaining for Ku80. (D and H) Immunostaining for DNA-PKcs. Original magnification x16 (A-D) and x400 (E-H).
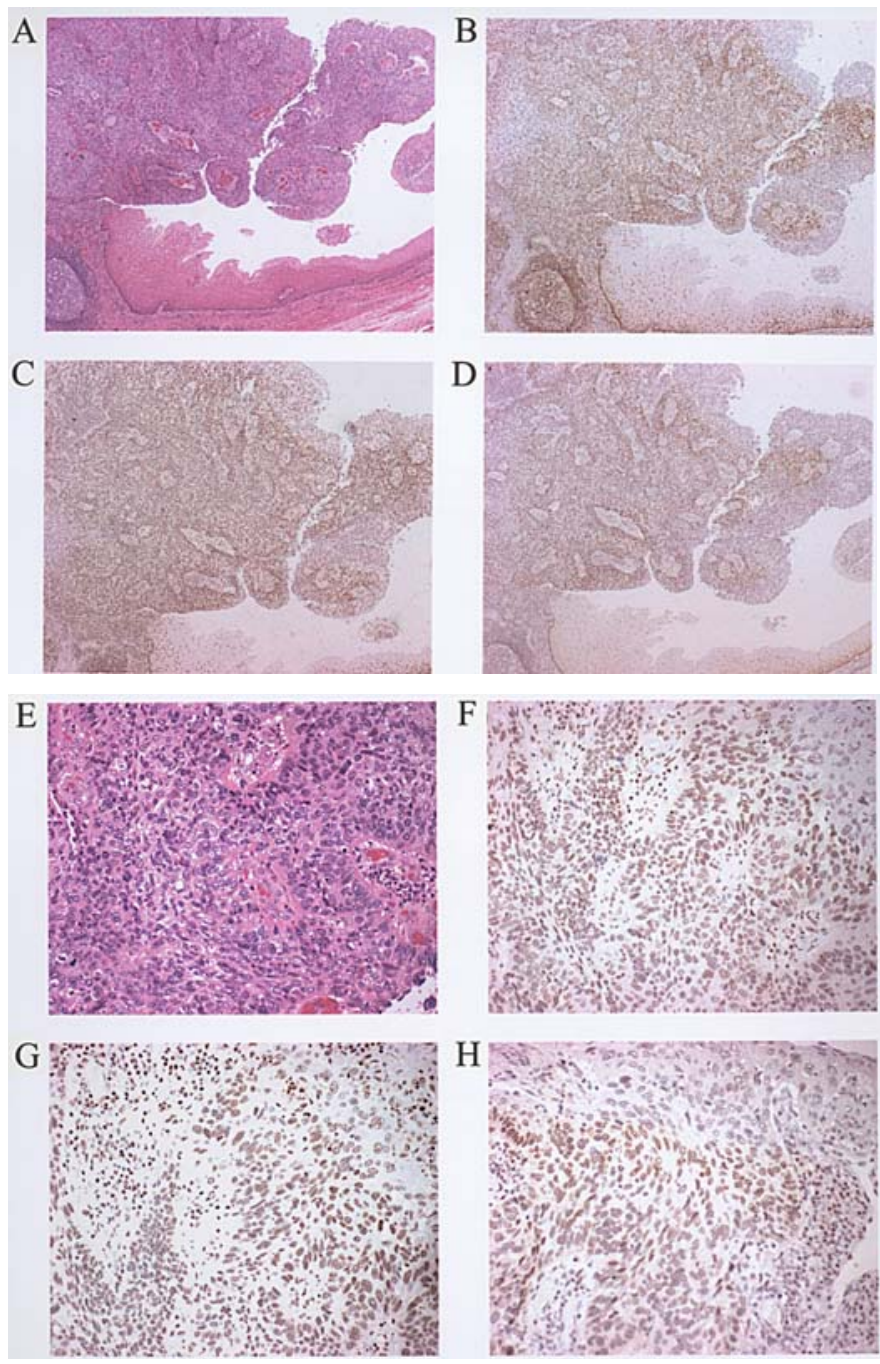

Figure 5. The expression of DNA-PK proteins in esophageal cancer tissues from patient No. 13. (A and E) Staining with hematoxylin and eosin. (B and F) Immunostaining for Ku70. (C and G) Immunostaining for Ku80. (D and H) Immunostaining for DNA-PKcs. Original magnification x16 (A-D) and x400 (E-H).

Sp1 biding sites are located in the promoter regions of a number of growth-regulated genes including insulin-like growth factor-binding protein 2 and vascular/endothelial growth factor $(31,32)$. Suppression of Sp1 by dominant negative Sp1 and Sp1-site-decoy oligonucleotides induces cell growth arrest $(32,33)$. These results suggest involvement of $\mathrm{Sp} 1$ in growth-regulation. In the present study, DNA-PK proteins were highly expressed in the nuclei of the basal cell layers of the normal epithelium and were not expressed in luminal cell layers (Fig. 3), which may reflect the growth of the stem cells located in the basal cell layers and the growth arrest of the differentiated cells in the luminal cell layers.

In the present study, the different portions in the same tumor showed different expression levels of DNA-PK proteins, and even each tumor cell showed different expression levels (Figs. 4 and 5). In esophageal cancer, intratumoral heterogeneity has been reported in expressions of many proteins includeing transcription factor Ets-1, cyclin B1, cyclin D1, retinoblastoma protein, cyclooxygenase-2, GAGE, NY-ESO-1, MAGE-A, SSX, E-cadherin and $\alpha$-catein (34-40). 
$\mathbf{A}$

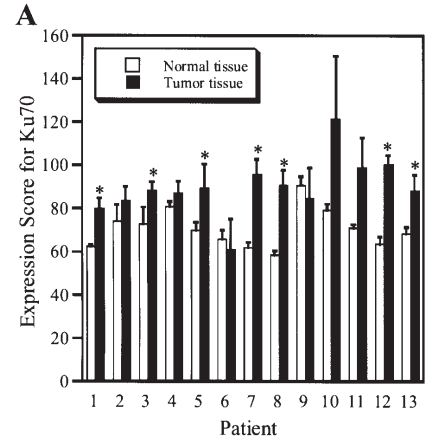

C

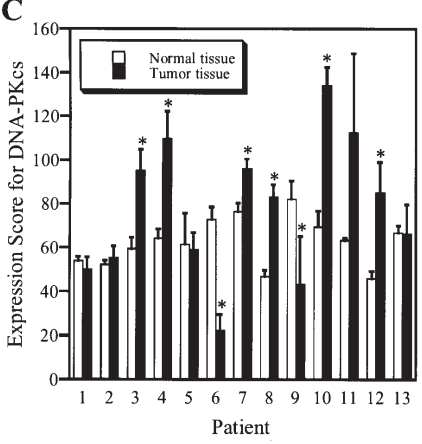

B

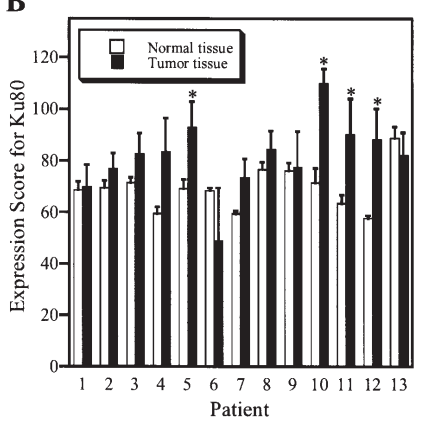

D

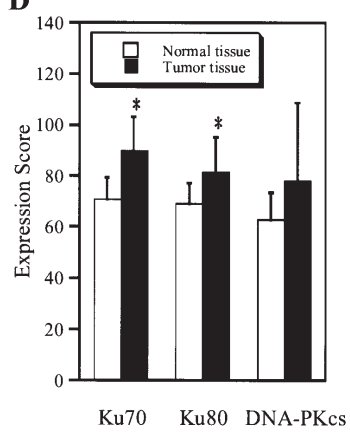

Figure 6. The expression of DNA-PK proteins in normal mucosae and tumor tissues estimated by the expression score. The expression score is the product of the intensity of expression multiplied by the percentage of cell expressing a given protein, and it assesses numerically the expression of each protein. Details are described in Materials and methods. (A and C) Expression scores for Ku70, Ku80 and DNA-PKcs in patients No. 1-13, respectively. Mean $\pm \mathrm{SD}$ of three expression scores. (D) Average values of the expression scores in the 13 patients. Mean $\pm \mathrm{SD},{ }^{*} \mathrm{P}<0.05$.

It has been reported that esophageal cancer is genetically heterogeneous and it consists of various sub-clones with different status of p53 gene as a result of tumor progression (41-43). This genetic heterogeneity in esophageal cancer may underlie the heterogeneous expression of the proteins mentioned above and that of DNA-PK proteins as reported in this study. Furthermore, the contribution of increased Sp1 activity to tumor progression has been reported (33). Upregulation of $\mathrm{Sp} 1$ in the process of tumor progression may increase the DNA-PK activity/protein levels of the tumor cells, as shown in Figs. 1, 2 and 6, and cause the acquisition of radioresistant phenotype.

In summary, DNA-PK activity was higher in the esophageal tumor tissues compared with the adjacent normal mucosae, and DNA-PK protein levels correlated with DNA-PK activity. Expression of DNA-PK proteins showed intratumoral heterogeneity in esophageal cancer tissues, making difficult the prediction of curability of the tumors after radiotherapy or chemotherapy by estimation of DNA-PK activity/protein levels in tumor specimens.

\section{References}

1. Gottlieb TM and Jackson SP: The DNA-dependent protein kinase: requirement for DNA ends and association with $\mathrm{Ku}$ antigen. Cell 72: 131-142, 1993.

2. Jeggo PA, Taccioli GE and Jackson SP: Menage a trois: double strand break repair, V(D)J recombination and DNA-PK. Bioessays 17: 949-957, 1995.

3. Lees-Miller SP, Godbout R, Chan DW, Weinfeld M, Day RS III, Barron GM and Allalunis-Turner J: Absence of p350 subunit of DNA-activated protein kinase from a radiosensitive human cell line. Science 267: 1183-1185, 1995.

4. Gu Y, Jin S, Gao Y, Weaver DT and Alt FW: Ku70-deficient embryonic stem cells have increased ionizing radiosensitivity, defective DNA end-binding activity, and inability to support V(D)J recombination. Proc Natl Acad Sci USA 94: 8076-8081, 1997.

5. Nussenzweig A, Sokol K, Burgman P, Li L and Li GC: Hypersensitivity of Ku80-deficient cell lines and mice to DNA damage: the effects of ionizing radiation on growth, survival, and development. Proc Natl Acad Sci USA 94: 13588-13593, 1997.

6. Gao Y, Chaudhuri J, Zhu C, Davidson L, Weaver DT and Alt FW: A targeted DNA-PKcs-null mutation reveals DNA-PKindependent functions for $\mathrm{KU}$ in $\mathrm{V}(\mathrm{D}) \mathrm{J}$ recombination. Immunity 9: 367-376, 1998.

7. Hosoi Y, Miyachi H, Matsumoto Y, Ikehata H, Komura J, Ishii K, Zhao HJ, Yoshida M, Takai Y, Yamada S, Suzuki N and Ono T: A phosphatidylinositol 3-kinase inhibitor wortmannin induces radioresistant DNA synthesis and sensitizes cells to bleomycin and ionizing radiation. Int J Cancer 78: 642-647, 1998.

8. Omori S, Takiguchi Y, Suda A, Sugimoto T, Miyazawa H, Takiguchi Y, Tanabe N, Tatsumi K, Kimura H, Pardington PE, Chen F, Chen DJ and Kuriyama T: Suppression of a DNA double-strand break repair gene, Ku70, increases radio- and chemosensitivity in a human lung carcinoma cell line. DNA Repair 1: 299-310, 2002.

9. Sak A, Stuschke M, Wurm R, Schroeder G, Sinn B, Wolf G and Budach V: Selective inactivation of DNA-dependent protein kinase with antisense oligodeoxynucleotides: consequences for the rejoining of radiation-induced DNA double-strand breaks and radiosensitivity of human cancer cell lines. Cancer Res 62: 6621-6624, 2002.

10. Collis SJ, Swartz MJ, Nelson WG and De Weese TL: Enhanced radiation and chemotherapy-mediated cell killing of human cancer cells by small inhibitory RNA silencing of DNA repair factors. Cancer Res 63: 1550-1554, 2003.

11. Polischouk AG, Cedervall B, Ljungquist S, Flygare J, Hellgren D, Grenman R and Lewensohn R: DNA double-strand break repair, DNA-PK, and DNA ligases in two human squamous carcinoma cell lines with different radiosensitivity. Int J Radiat Oncol Biol Phys 43: 191-198, 1999.

12. Allalunis-Turner MJ, Lintott LG, Barron GM, Day RS and Lees-Miller SP: Lack of correlation between DNA-dependent protein kinase activity and tumor cell radiosensitivity. Cancer Res 55: 5200-5202, 1995 .

13. Kasten U, Plottner N, Johansen J, Overgaard J and Dikomey E: $\mathrm{Ku} 70 / 80$ gene expression and DNA-dependent protein kinase (DNA-PK) activity do not correlate with double-strand break (dsb) repair capacity and cellular radiosensitivity in normal human fibroblasts. Br J Cancer 79: 1037-1041, 1999.

14. Sirzen F, Nilsson A, Zhivotovsky B and Lewensohn R: DNAdependent protein kinase content and activity in lung carcinoma cell lines: correlation with intrinsic radiosensitivity. Eur J Cancer 35: 111-116, 1999.

15. Vaganay-Juery S, Muller C, Marangoni E, Abdulkarim B, Deutsch E, Lambin P, Calsou P, Eschwege F, Salles B, Joiner M and Bourhis J: Decreased DNA-PK activity in human cancer cells exhibiting hypersensitivity to low-dose irradiation. Br J Cancer 83: 514-518, 2000.

16. Bjork-Eriksson T, West C, Nilsson A, Magnusson B, Svensson M, Karlsson E, Slevin N, Lewensohn R and Mercke C: The immunohistochemical expression of DNA-PKCS and $\mathrm{Ku}(\mathrm{p} 70 / \mathrm{p} 80)$ in head and neck cancers: relationships with radiosensitivity. Int $\mathbf{J}$ Radiat Oncol Biol Phys 45: 1005-1010, 1999.

17. Zhao HJ, Hosoi Y, Miyachi H, Ishii K, Yoshida M, Nemoto K, Takai Y, Yamada S, Suzuki N and Ono T: DNA-dependent protein kinase activity correlates with Ku70 expression and radiation sensitivity in esophageal cancer cell lines. Clin Cancer Res 6: 1073-1078, 2000.

18. Wilson CR, Davidson SE, Margison GP, Jackson SP, Hendry JH and West CM: Expression of Ku70 correlates with survival in carcinoma of the cervix. Br J Cancer 83: 1702-1706, 2000.

19. Sakata K, Matsumoto Y, Tauchi H, Satoh M, Oouchi A, Nagakura H, Koito K, Hosoi Y, Suzuki N, Komatsu K and Hareyama M: Expression of genes involved in repair of DNA double-strand breaks in normal and tumor tissues. Int J Radiat Oncol Biol Phys 49: 161-167, 2001. 
20. Komuro Y, Watanabe T, Hosoi Y, Matsumoto Y, Nakagawa K, Tsuno N, Kazama S, Kitayama J, Suzuki N and Nagawa H: The expression pattern of $\mathrm{Ku}$ correlates with tumor radiosensitivity and disease free survival in patients with rectal carcinoma. Cancer 95: 1199-1205, 2002

21. Hosoi Y, Watanabe T, Nakagawa K, Matsumoto Y, Enomoto A, Morita A, Nagawa H and Suzuki N: Up-regulation of DNAdependent protein kinase activity and $\mathrm{Sp} 1$ in colorectal cancer. Int J Oncol 25: 461-468, 2004.

22. Murnane JP: Inducible gene expression by DNA rearrangements in human cells. Mol Cell Biol 6: 549-558, 1986.

23. Finnie NJ, Gottlieb TM, Blunt T, Jeggo PA and Jackson SP: DNA-dependent protein kinase activity is absent in xrs-6 cells: implications for site-specific recombination and DNA doublestrand break repair. Proc Natl Acad Sci USA 92: 320-324, 1995.

24. Dignam JD, Lebovitz RM and Roeder RG: Accurate transcription initiation by RNA polymerase II in a soluble extract from isolated mammalian nuclei. Nucleic Acids Res 11: 1475-1489, 1983.

25. Hosoi Y, Kawamura M, Ido T, Takai Y, Ishii K, Nemoto K, Ono T, Kimura S and Sakamoto K: Sensitization of cells to ionizing radiation by chlorin e6 $\mathrm{Na}$. Radiat Oncol Investig 6: 151-156, 1998.

26. Rigas B, Borgo S, Elhosseiny A, Balatsos V, Manika Z, Shinya H, Kurihara N, Go M and Lipkin M: Decreased expression of DNA-dependent protein kinase, a DNA repair protein, during human colon carcinogenesis. Cancer Res 61: 8381-8384, 2001.

27. Chino O, Makuuchi H, Shimada H, Machimura T, Mitomi T and Osamura RY: Assessment of the proliferative activity of superficial esophageal carcinoma using MIB-1 immunostaining for the Ki-67 antigen. J Surg Oncol 67: 18-24, 1998.

28. Yoshida M, Hosoi Y, Miyachi H, Ishii N, Matsumoto Y, Enomoto A, Nakagawa K, Yamada S, Suzuki N and Ono T: Roles of DNA-dependent protein kinase and ATM in cell-cycledependent radiation sensitivity in human cells. Int J Radiat Biol 78: 503-512, 2002.

29. Ludwig DL, Chen F, Peterson SR, Nussenzweig A, Li GC and Chen DJ: Ku80 gene expression is Sp1-dependent and sensitive to CpG methylation within a novel cis element. Gene 199: 181-194, 1997.

30. Fujimoto M, Matsumoto N, Tsujita T, Tomita H, Kondo S, Miyake N, Nakano M and Niikawa N: Characterization of the promoter region, first ten exons and nine intron-exon boundaries of the DNA-dependent protein kinase catalytic subunit gene, DNA-PKcs (XRCC7). DNA Res 4: 151-154, 1997.

31. Milanini J, Vinals F, Pouyssegur J and Pages G: p42/p44 MAP kinase module plays a key role in the transcriptional regulation of the vascular endothelial growth factor gene in fibroblasts. J Biol Chem 273: 18165-18172, 1998.

32. Kutoh E, Margot JB and Schwander J: Identification and characterization of the putative retinoblastoma control element of the rat insulin-like growth factor binding protein-2 gene. Cancer Lett 136: 187-194, 1999.
33. Ishibashi H, Nakagawa K, Onimaru M, Castellanous EJ, Kaneda Y, Nakashima Y, Shirasuna K and Sueishi K: Sp1 decoy transfected to carcinoma cells suppresses the expression of vascular endothelial growth factor, transforming growth factor beta1, and tissue factor and also cell growth and invasion activities. Cancer Res 60: 6531-6536, 2000.

34. Saeki H, Kuwano H, Kawaguchi H, Ohno S and Sugimachi K: Expression of ets-1 transcription factor is correlated with penetrating tumor progression in patients with squamous cell carcinoma of the esophagus. Cancer 89: 1670-1676, 2000.

35. Murakami H, Furihata M, Ohtsuki Y and Ogoshi S: Determination of the prognostic significance of cyclin B1 overexpression in patients with esophageal squamous cell carcinoma. Virchows Arch 434: 153-158, 1999

36. Ishikawa T, Furihata M, Ohtsuki Y, Murakami H, Inoue A and Ogoshi S: Cyclin D1 overexpression related to retinoblastoma protein expression as a prognostic marker in human oesophageal squamous cell carcinoma. Br J Cancer 77: 92-97, 1998.

37. Xing EP, Yang GY, Wang LD, Shi ST and Yang CS: Loss of heterozygosity of the $\mathrm{Rb}$ gene correlates with $\mathrm{pRb}$ protein expression and associates with p53 alteration in human esophageal cancer. Clin Cancer Res 5: 1231-1240, 1999.

38. Abdalla SI, Sanderson IR and Fitzgerald RC: Effect of inflammation on cyclooxygenase (COX)-2 expression in benign and malignant oesophageal cells. Carcinogenesis 26: 1627$1633,2005$.

39. Akcakanat A, Kanda T, Tanabe T, Komukai S, Yajima K, Nakagawa S, Ohashi M and Hatakeyama K: Heterogeneous expression of GAGE, NY-ESO-1, MAGE-A and SSX proteins in esophageal cancer: Implications for immunotherapy. Int $\mathbf{J}$ Cancer 118: 123-128, 2006.

40. Kadowaki T, Shiozaki H, Inoue M, Tamura S, Oka H, Doki Y, Iihara K, Matsui S, Iwazawa T and Nagafuchi A: E-cadherin and alpha-catenin expression in human esophageal cancer. Cancer Res 54: 291-296, 1994.

41. Kaketani K, Saito T, Kuwahara A, Shimoda K, Miyahara M, Chikuba K, Etoh K and Kobayashi M: DNA stem line heterogeneity in esophageal cancer accurately identified by flow cytometric analysis. Cancer 72: 3564-3570, 1993.

42. Kuwabara S, Ajioka Y, Watanabe H, Hitomi J, Nishikura K and Hatakeyama K: Heterogeneity of p53 mutational status in esophageal squamous cell carcinoma. Jpn J Cancer Res 89: 405-410, 1998.

43. Shi ST, Yang GY, Wang LD, Xue Z, Feng B, Ding W, Xing EP and Yang CS: Role of p53 gene mutations in human esophageal carcinogenesis: results from immunohistochemical and mutation analyses of carcinomas and nearby non-cancerous lesions. Carcinogenesis 20: 591-597, 1999. 